\title{
Acute intestinal obstruction secondary to left paraduodenal hernia: a case report and literature review
}

\author{
Waleed Al-Khyatt ${ }^{1,2^{*}}$, Smeer Aggarwal ${ }^{1}$, James Birchall ${ }^{1}$ and Timothy E Rowlands ${ }^{1}$
}

\begin{abstract}
Introduction: An internal hernia is a protrusion of bowel through a normal or abnormal orifice in the peritoneum or mesentery. Although they are considered as a rare cause of intestinal obstruction, paraduodenal hernias are the most common type of congenital hernias.

Methods: A literature search using PubMed was performed to identify all published cases of left paraduodenal hernia (LPDH).

Results: In Literature search between 1980 and 2012 using PubMed revealed only 44 case reports before the present one. Median age was 47 years (range $18-82$ years). Nearly 50\% reported previous mild symptoms. Two-third of patients required emergency surgery in form of laparotomy or laparoscopic repair. Reduction of hernia contents with widening or suture repair of the hernia orifice were the most common standards in surgical management of LPDH.

Conclusion: Intestinal obstruction secondary to internal hernias is a rare presentation. High index of suspicion and preoperative imaging are essential to make an early diagnosis in order to improve outcome.
\end{abstract}

\section{Introduction}

Internal hernia is, either congenital or acquired, a rare cause of small-bowel obstruction, with a reported incidence of less than 2\% [1]. Paraduodenal hernias, which are a type of internal hernia, occur due to malrotation of midgut and form a potential space near the ligament of Treitz [2]. Incidental finding at laparotomy or on imaging is the most common presentation of these hernias [3]. Nevertheless, Paraduodenal hernias can lead to bowel obstruction, ischemia, and perforation with a high mortality. Left paraduodenal hernia (LPDH) is the most common types of congenital hernias and accounts for more than $40 \%$ of all cases [4]. Clinical diagnosis of LPDH is a real challenge as symptoms are entirely nonspecific. Therefore, a timely and correct diagnosis with a rapid diagnostic tool is mandatory [5]. In this review we

\footnotetext{
*Correspondence: mzxwa@nottingham.ac.uk

'Division of General Surgery and Radiology, Royal Derby Hospital, Uttoxetter Road, Derby DE22 3DT, UK

${ }^{2}$ Division of Surgery, School of Graduate Entry Medicine and Health, University of Nottingham, Royal Derby Hospital, Uttoxeter Road, Derby DE22 3DT, UK
}

\section{Biomed Central

(c) 2013 Al-Khyatt et al.; licensee BioMed Central Ltd. This is an Open Access article distributed under the terms of the Creative Commons Attribution License (http://creativecommons.org/licenses/by/2.0), which permits unrestricted use, distribution, and reproduction in any medium, provided the original work is properly cited. discuss the clinical presentation and management of small bowel obstruction secondary to LPDH.

\section{Case presentation}

A 47 -year-old Caucasian male admitted with increasing severe colicky abdominal pain and bile stained vomiting of 2 days duration. He had no previous significant past medical or surgical history. He also denied any history of weight loss, or recent changes in his bowel habit. However, $\mathrm{He}$ described at least 4 previous episodes of upper abdominal distension and vomiting with spontaneous resolution over the previous 2 years. On examination, the patient appeared in moderate pain with normal vital signs. Abdominal examination revealed abdominal distension with a tender mass in the left upper quadrant. Laboratory studies were essentially normal. An urgent abdominal CT scan confirmed the diagnosis of small bowel obstruction secondary to what looked like a hernia into the left paraduodenal fossa (fossa of Landzert) (Figure 1). At laparotomy, a hernia sac of $25 \mathrm{~cm}$ in diameter arising from a defect just to the left of the fourth part of the duodenum was found, consistent with 


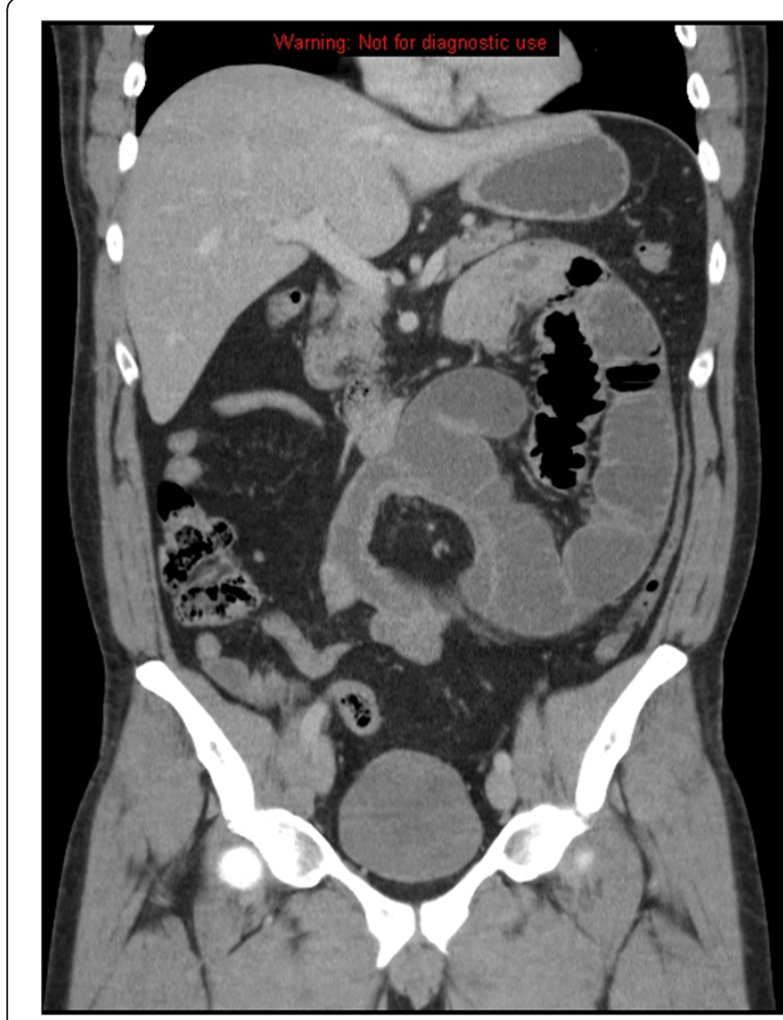

Figure 1 Axial enhanced CT demonstrates a cluster of dilated jejunal loops located in the Landzert's fossa.

a LPDH (Figure 2A). The intestinal loops were herniated through that congenital defect and were not spontaneously reducible. A band containing the inferior mesenteric vein was deemed necessary to divide at the time in order to widen the orifice of the defect and to retrieve the dilated small bowel from the hernia sac (Figure 2B). The hernia sac was excised completely down to the base at the mesentery of large bowel (Figure 2C). The patient had uneventful postoperative recovery and discharged home 5 days later. At 8 weeks post-surgery, he was back to full normal activities with a well-healed laparotomy scar.

\section{Discussion}

Internal herniation of the small bowel is a relatively rare cause of intestinal obstruction and accounts for less than $2 \%$ of all causes [1]. Among all congenital hernias, paraduodenal hernias are the most common type with an overall incidence of approximately $50 \%$ of all internal hernias $[1,4,6]$. LPDH (hernia of Lanzert) is about three times more common than the right counterpart (Waldayer's hernia) [7]. LPDH arises from the fossa of Landzert, a congenital defect which presents in approximately $2 \%$ of the population, located to the left of the fourth part of the duodenum, posterior to the inferior mesenteric vein and left branches of the middle colic artery (Figure 2A) $[2,8,9]$. Small bowel loops (usually jujenum) prolapse posteroinferiorly through the fossa to the left of the fourth part of the duodenum into the left portion of the transverse mesocolon. Hence, the herniated small bowel loops may become trapped within this mesenteric sac (Figure 2C) $[4,10]$.

Literature search between 1980 and 2012 using PubMed revealed only 44 case reports before the present one [2,5,11-49] (Table 1). Median age at presentation was 47 (range of 18-82 years old) with male to female ratio of 3:1. In this review, patients often presented with symptoms and signs of typical of internal hernias complicated by bowel obstruction, strangulation, and/or necrosis. Besides, $43 \%$ of patients reported a prior history of recurring abdominal pain with symptoms. Only three cases presented with a palpable mass in the left upper quadrant at time of presentation.

Radiological diagnosis of LPDH prior to surgery was achieved in $43 \%$ of patients. On CT scan, typical appearance of LPDH is an encapsulated sac containing clusters of dilated small bowel loops at or above the ligament of Treitz with a mass like effect compressing
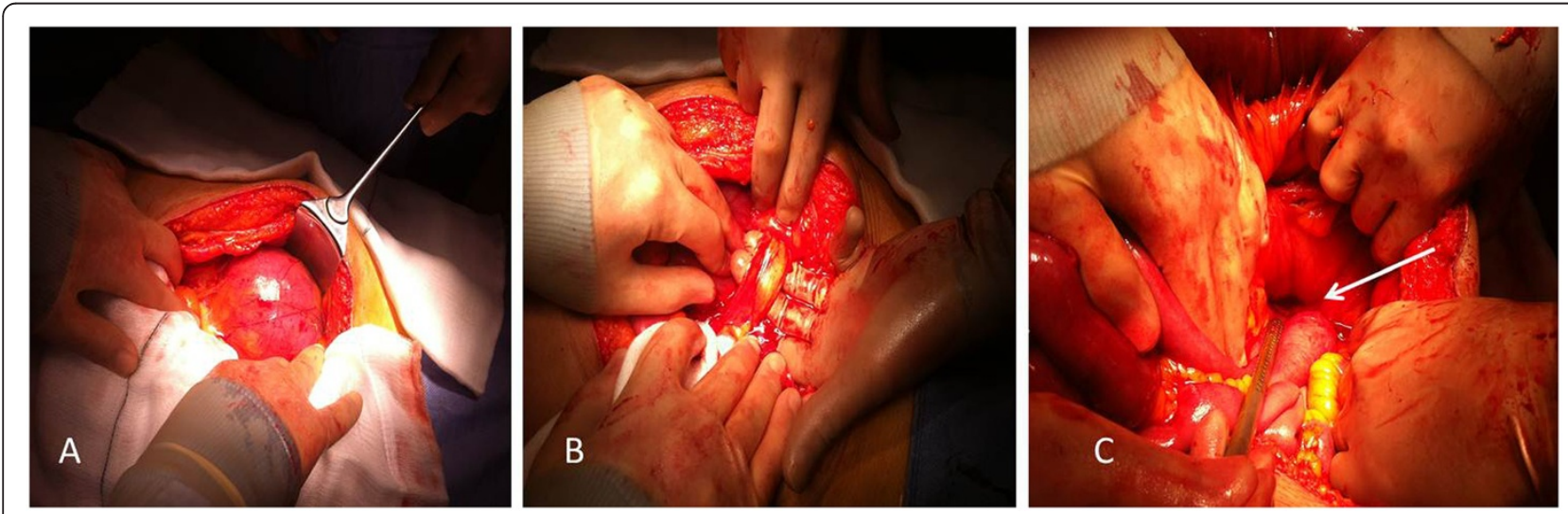

Figure 2 A) Operative finding of hernia sac in the fossa of Landzert containing small bowel loops. B) Abnormal congenital band (ligament of Treitz) containing inferior mesenteric vein. C) A potential space in the large bowel mesentery (arrow) with hernia sac was laid opened. 
Table 1 Reported cases of left paraduodenal hernia

\begin{tabular}{|c|c|c|c|c|c|c|c|c|}
\hline Author, year & $\begin{array}{c}\text { Age } \\
\text { (years) }\end{array}$ & Gender & $\begin{array}{c}\text { Chronic } \\
\text { symptoms }\end{array}$ & $\begin{array}{c}\text { Small bowel } \\
\text { obstruction }\end{array}$ & $\begin{array}{l}\text { Left paraduodenal } \\
\text { hernia confirmed } \\
\text { on imaging }\end{array}$ & $\begin{array}{l}\text { Emergency/ } \\
\text { elective surgery }\end{array}$ & Laparotomy & Laparoscopic \\
\hline Chatterjee et al., 2012 [11] & 55 & Male & - & Yes & - & Emergency & Yes & - \\
\hline Bhatti et al., 2012 [12] & 18 & Female & - & Yes & - & Emergency & Yes & - \\
\hline Akbulut et al., 2012 [13] & 42 & Male & - & Yes & - & Emergency & Yes & - \\
\hline Hussein et al. 2012 [14] & 59 & Female & - & Yes & Yes & Emergency & - & Yes \\
\hline Fernandez-Ray et al. 2011 [15] & 39 & Male & - & Yes & Yes & Emergency & Yes & - \\
\hline Downes et al., 2010 [16] & 47 & Male & Yes & - & - & Emergency & Yes & - \\
\hline Parmar et al.,2010 [17] & 38 & Male & Yes & - & - & Elective & - & Yes \\
\hline Khalaileh et al., 2010 [5] & 53 & Female & - & Yes & Yes & Emergency & - & yes \\
\hline Yun et al., 2010 [18] & 28 & Male & - & - & Yes & Emergency & Yes & - \\
\hline Uchiyam et al., 2009 [19] & 80 & Female & Yes & - & - & Elective & - & Yes \\
\hline Poultsides et al., 2009 [20] & 67 & Female & - & Yes & - & Emergency & - & Yes \\
\hline Kuzinkovas et al., 2008 [21] & 59 & Male & - & - & - & Elective & Yes & - \\
\hline Peters et al., 2008 [22] & 76 & Male & - & Yes & Yes & Emergency & Yes & - \\
\hline Jeong et al., 2008 [23] & 52 & Male & - & Yes & - & Emergency & - & Yes \\
\hline Jeong et al., 2008 [23] & 58 & Female & - & Yes & - & Emergency & - & Yes \\
\hline Palanivelu et al., 2008 [24] & - & Male & - & - & Yes & Elective & - & Yes \\
\hline Palanivelu et al., 2008 [24] & - & Male & - & Yes & Yes & Emergency & - & Yes \\
\hline Palanivelu et al., 2008 [24] & - & Female & - & Yes & Yes & Elective & - & Yes \\
\hline Shoji et al., 2007 [25] & 60 & Male & - & - & - & Emergency & - & Yes \\
\hline Papaziogas et al., 2007 [26] & 35 & Female & - & Yes & - & Emergency & Yes & - \\
\hline Moon et al., 2006 [27] & 18 & Male & - & Yes & - & Emergency & - & Yes \\
\hline Brehm et al. 2006 [28] & 54 & Female & Yes & - & Yes & Emergency & Yes & - \\
\hline Thoma et al., 2006 [29] & 72 & Female & Yes & - & - & Elective & Yes & - \\
\hline Cingi et al., 2006 [30] & 30 & Male & Yes & - & - & Emergency & Yes & - \\
\hline Kurachi et al., 2006 [31] & 47 & Female & - & Yes & - & Emergency & Yes & - \\
\hline Huang et al., 2005 [32] & 24 & Male & Yes & Yes & - & Emergency & Yes & - \\
\hline Ovali et al., 2005 [33] & 52 & Female & Yes & - & Yes & Refused surgery & - & - \\
\hline Fukunaga et al., 2004 [34] & 51 & Male & Yes & Yes & Yes & Emergency & - & Yes \\
\hline Rollins et al., 2004 [35] & 21 & Male & Yes & - & Yes & Elective & - & Yes \\
\hline Patti et al., 2004 [36] & 46 & Male & Yes & - & - & Elective & Yes & - \\
\hline Catalano et al., 2004 [37] & 82 & Male & - & Yes & Yes & Emergency & Yes & - \\
\hline Goodney et al., 2004 [38] & 75 & Male & Yes & - & - & Elective & Yes & - \\
\hline Tong et al., 2002 [39] & 30 & Male & Yes & - & - & Elective & Yes & - \\
\hline Nishida et al., 2001 [40] & 47 & Male & Yes & - & Yes & Elective & Yes & Yes \\
\hline Patil et al., 1999 [41] & 29 & Female & - & - & Yes & Emergency & Yes & - \\
\hline Schaffler et al., 1999 [42] & 26 & Male & Yes & - & Yes & Elective & Yes & - \\
\hline Uematsu et al., 1998 [43] & 44 & Male & Yes & - & - & Elective & - & Yes \\
\hline Hirasaki et al., 1998 [44] & 28 & Female & Yes & - & Yes & Elective & Yes & - \\
\hline Mcdonagh et al., 1996 [45] & 52 & Male & - & Yes & - & Emergency & Yes & - \\
\hline Suchato et al., 1996 [46] & 40 & Male & - & Yes & - & Emergency & Yes & - \\
\hline Suchato et al., 1996 [46] & 52 & Male & Yes & - & - & Emergency & Yes & - \\
\hline Warshauer et al., 1992 [47] & 42 & Female & Yes & - & Yes & Elective & Yes & - \\
\hline Toit et al., 1986 [48] & 22 & Male & - & Yes & - & Emergency & Yes & - \\
\hline Tireli et al., 1982 [49] & 18 & Male & - & Yes & - & Emergency & Yes & - \\
\hline
\end{tabular}


the posterior gastric wall and distal part of the duodenum. Besides, there is engorgement and crowding of the mesenteric vessels with frequent right displacement of the main mesenteric trunk and depression of the transverse colon (Figure 1).

Once a LPDH is identified, operative treatment is necessary, as patients with a LPDH have a $50 \%$ lifetime risk of developing small bowel obstruction with a $20-50 \%$ mortality rate for acute presentations [6,8]. In this review, 28 patients $(67 \%)$ underwent emergency surgery. Of those 43 patients, 15 patients had laparoscopic repair of LPDH. Surgical intervention included reduction of the herniated small bowel loops and closure of the hernia orifice with non-absorbable sutures or a mesh [5,24]. A different possibility was to widen the hernia orifice to prevent future incarceration of bowel loops [5]. Often, there is a close anatomical relationship between the inferior mesenteric vein which bound the hernia anteriorly, and the hernia orifice $[5,24]$. Therefore, division of the inferior mesenteric vessels at the neck of the sac may be necessary, as in this case, when the incarcerated bowel could not be reduced easily from the hernia [24].

\section{Conclusion}

Left paraduodenal fossa hernia is a relatively a rare cause of small bowel obstruction. In young patients with recurrent small bowel obstruction with no previous surgical history, it is crucial to consider internal hernias in the differential diagnosis. Furthermore, a timely and correct diagnosis is together with prompt surgical intervention is essential for achieving patient's cure and prevents future complications.

\section{Consent}

Written informed consent was obtained from the patient for publication of this case report and accompanying images. A copy of the written consent is available for review by the Editor-in-Chief of this journal.

\section{Competing interests}

The authors declare that they have no competing interests.

\section{Authors' contributions}

WAK, SA, JB, and TER prepared the manuscript. TER outlined the manuscript's layout and supervised the work. All authors read and approved the final manuscript.

Received: 24 September 2012 Accepted: 14 January 2013 Published: 16 January 2013

\section{References}

1. Blachar A, Federle MP, Dodson SF: Internal hernia: clinical and imaging findings in 17 patients with emphasis on CT criteria. Radiology 2001, 218(1):68-74.

2. Berardi RS: Paraduodenal hernias. Surg Gynecol Obstet 1981, 152(1):99-110.

3. Olazabal A, Guasch I, Casas D: Case report: CT diagnosis of nonobstructive left paraduodenal hernia. Clin Radiol 1992, 46(4):288-289.

4. Martin LC, Merkle EM, Thompson WM: Review of internal hernias: radiographic and clinical findings. AJR Am J Roentgenol 2006, 186(3):703-717.
5. Khalaileh $A$, et al: Left laparoscopic paraduodenal hernia repair. Surg Endosc 2010, 24(6):1486-1489.

6. Blachar A, et al: Radiologist performance in the diagnosis of internal hernia by using specific $\mathrm{CT}$ findings with emphasis on transmesenteric hernia. Radiology 2001, 221(2):422-428.

7. Khan MA, Lo AY, Vande Maele DM: Paraduodenal hernia. Am Surg 1998 64(12):1218-1222.

8. Zonca $P$, et al: Treitz's hernia. Hernia 2008, 12(5):531-534

9. Willwerth BM, Zollinger RM Jr, Izant RJ Jr: Congenital mesocolic (paraduodenal) hernia. Embryologic basis of repair. Am J Surg 1974, 128(3):358-361.

10. Armstrong $O$, et al: Internal hernias: anatomical basis and clinical relevance. Surg Radiol Anat 2007, 29(4):333-337.

11. Chatterjee S, Kumar S, Gupta S: Acute intestinal obstruction: a rare aetiology. Case Rep Surg 2012, 2012:501209.

12. Hafeez Bhatti $A B$, Khan MA: Left paraduodenal hernia: a rare cause of large bowel obstruction and gangrene. J Coll Physicians Surg Pak 2012, 22(4):250-251

13. Akbulut S: Unusual cause of intestinal obstruction: left paraduodenal hernia. Case Report Med 2012, 2012:529246.

14. Hussein $M$, et al: Laparoscopic repair of a left paraduodenal hernia presenting with acute bowel obstruction: report of a case. Surg Laparosc Endosc Percutan Tech 2012, 22(1):e28-e30.

15. Fernandez-Rey CL, Martinez-Alvarez C, Concejo-Cutoli P: Acute abdomen secondary to left paraduodenal hernia: diagnostic by multislice computer tomography. Rev Esp Enferm Dig 2011, 103(1):38-39.

16. Downes R, Cawich SO: A case of a paraduodenal hernia. Int I Surg Case Rep 2010, 1(2):19-21.

17. Parmar BP, Parmar RS: Laparoscopic management of left paraduodenal hernia. J Minim Access Surg 2010, 6(4):122-124.

18. Yun MY, et al: Left paraduodenal hernia presenting with atypical symptoms. Yonsei Med J, 51(5):787-789.

19. Uchiyama $S$, et al: An unusual variant of a left paraduodenal hernia diagnosed and treated by laparoscopic surgery: report of a case. Surg Today 2009, 39(6):533-535.

20. Poultsides GA, et al: Image of the month. Left paraduodenal hernia. Arch Surg 2009, 144(3):287-288.

21. Kuzinkovas $V$, et al: Paraduodenal hernia: a rare cause of abdominal pain. Can J Surg 2008, 51(6):E127-E128.

22. Peters SA, et al: Radiology for the surgeon: Soft-tissue case 60. Can J Surg 2008, 51(2):151-152

23. Jeong GA, et al: Laparoscopic repair of paraduodenal hernia: comparison with conventional open repair. Surg Laparosc Endosc Percutan Tech 2008, 18(6):611-615

24. Palanivelu C, et al: Laparoscopic management of paraduodenal hernias: mesh and mesh-less repairs. A report of four cases. Hernia 2008, 12(6):649-653.

25. Shoji T, et al: Left paraduodenal hernia successfully treated with laparoscopic surgery: a case report. Case Rep Gastroenterol 2007, 1(1):71-76.

26. Papaziogas $B$, et al: Idiopathic hypertrophic pyloric stenosis combined with left paraduodenal hernia in an adult. Med Princ Pract 2007, 16(2):151-154

27. Moon $\mathrm{CH}$, Chung MH, Lin KM: Diagnostic laparoscopy and laparoscopic repair of a left paraduodenal hernia can shorten hospital stay. JSLS 2006, 10(1):90-93

28. Brehm V, Smithuis R, Doornebosch PG: A left paraduodenal hernia causing acute bowel obstruction: a case report. Acta Chir Belg 2006, 106(4):436-437.

29. Thoma M, et al: Left paraduodenal hernia: a case report. Acta Chir Belg 2006, 106(4):433-435.

30. Cingi A, et al: Left-sided paraduodenal hernia: report of a case. Surg Today 2006, 36(7):651-654.

31. Kurachi $\mathrm{K}$, et al: Left paraduodenal hernia in an adult complicated by ascending colon cancer: a case report. World J Gastroenterol 2006, 12(11):1795-1797.

32. Huang $Y M$, et al: Left paraduodenal hernia presenting as recurrent small bowel obstruction. World J Gastroenterol 2005, 11(41):6557-6559.

33. Ovali GY, et al: Transient left paraduodenal hernia. Comput Med Imaging Graph 2005, 29(6):459-461.

34. Fukunaga $M$, et al: Laparoscopic surgery for left paraduodenal hernia. J Laparoendosc Adv Surg Tech A 2004, 14(2):111-115.

35. Rollins MD, Glasgow RE: Left paraduodenal hernia. J Am Coll Surg 2004, 198(3):492-493. 
36. Patti $R$, et al: Paraduodenal hernia: an uncommon cause of recurrent abdominal pain. G Chir 2004, 25(5):183-186.

37. Catalano $O A$, et al: Internal hernia with volvulus and intussusception: case report. Abdom Imaging 2004, 29(2):164-165.

38. Goodney PP, Pindyck F: Paraduodenal hernia and jejunal diverticulosis. J Gastroenterol Hepatol 2004, 19(2):229-231.

39. Tong RS, Sengupta S, Tjandra JJ: Left paraduodenal hernia: case report and review of the literature. ANZ J Surg 2002, 72(1):69-71.

40. Nishida T, et al: Unusual type of left paraduodenal hernia caused by a separated peritoneal membrane. J Gastroenterol 2002, 37(9):742-744.

41. Patil R, Smith C, Brown MD: Paraduodenal hernia presenting as unexplained recurrent abdominal pain. Am J Gastroenterol 1999, 94(12):3614-3615.

42. Schaffler GJ, et al: Anterior and upward displacement of the inferior mesenteric vein:a new diagnostic clue to left paraduodenal hernias? Abdom Imaging 1999, 24(1):29-31.

43. Uematsu T, et al: Laparoscopic repair of a paraduodenal hernia. Surg Endosc 1998, 12(1):50-52.

44. Hirasaki $\mathrm{S}$, et al: Unusual variant of left paraduodenal hernia herniated into the mesocolic fossa leading to jejunal strangulation. J Gastroenterol 1998, 33(5):734-738

45. McDonagh $T$, Jelinek GA: Two cases of paraduodenal hernia, a rare internal hernia. J Accid Emerg Med 1996, 13(1):64-68.

46. Suchato C, Pekanan P, Panjapiyakul C: CT findings in symptomatic left paraduodenal hernia. Abdom Imaging 1996, 21(2):148-149.

47. Warshauer DM, Mauro MA: CT diagnosis of paraduodenal hernia. Gastrointest Radiol 1992, 17(1):13-15.

48. Du Toit DF, Pretorius CF: Left paraduodenal hernia with acute abdominal symptoms. A case report. S Afr Med J 1986, 70(4):233-234

49. Tireli M: Left paraduodenal hernia. Br J Surg 1982, 69(2):114.

doi:10.1186/1749-7922-8-5

Cite this article as: Al-Khyatt et al.: Acute intestinal obstruction secondary to left paraduodenal hernia: a case report and literature review. World Journal of Emergency Surgery 2013 8:5.

\section{Submit your next manuscript to BioMed Central and take full advantage of:}

- Convenient online submission

- Thorough peer review

- No space constraints or color figure charges

- Immediate publication on acceptance

- Inclusion in PubMed, CAS, Scopus and Google Scholar

- Research which is freely available for redistribution 